\title{
Incorporating ethnicity into genetic risk assessment for Alzheimer disease: the REVEAL study experience
}

Kurt D. Christensen, $M P H^{1}$, J. Scott Roberts, $P h D^{1}$, Charmaine D. M. Royal, PhD', Grace-Ann Fasaye, ScM, CGC ${ }^{3}$, Thomas Obisesan, $M D^{4}$, L. Adrienne Cupples, $P h D^{5,6}$, Peter J. Whitehouse, $M D, P h D^{7}$, Melissa Barber Butson, ScM, CGC , Erin Linnenbringer, MS, CGC $C^{1}$, Norman R. Relkin, MD, PhD ${ }^{8}$, Lindsay Farrer, $P h D^{5,6,9,10}$, Robert Cook-Deegan, $M D^{2}$, and Robert C. Green, $M D, M P H^{6,9}$

\begin{abstract}
Purpose: To describe how investigators in a multisite randomized clinical trial addressed scientific and ethical issues involved in creating risk models based on genetic testing for African American participants. Methods: The following informed our decision whether to stratify risk assessment by ethnicity: evaluation of epidemiological data, appraisal of benefits and risks of incorporating ethnicity into calculations, and feasibility of creating ethnicityspecific risk curves. Once the decision was made, risk curves were created based on data from a large, diverse study of first-degree relatives of patients with Alzheimer disease. Results: Review of epidemiological data suggested notable differences in risk between African Americans and whites and that Apolipoprotein E genotype predicts risk in both groups. Discussions about the benefits and risks of stratified risk assessments reached consensus that estimates based on data from whites should not preclude enrolling African Americans, but population-specific risk curves should be created if feasible. Risk models specific to ethnicity, gender, and Apolipoprotein E genotype were subsequently developed for the randomized clinical trial that oversampled African Americans. Conclusion: The Risk Evaluation and Education for Alzheimer Disease study provides an instructive example of a process to develop risk assessment protocols that are sensitive to the implications of genetic testing for multiple ethnic groups with differing levels of risk. Genet Med 2008:10(3):207-214.
\end{abstract}

Key Words: Alzheimer, ethnicity, genetics, risk, APOE

Researchers are identifying a growing number of genetic markers that are associated with increased or decreased risk for common, complex diseases. Consequently, the development of genetic risk assessment and risk communication strategies are areas of critical importance, especially given that laypersons often have a difficult time in understanding probabilistic information. ${ }^{1,2}$ Protocols for disclosing genetic information have been developed and refined for various forms of cancer, ${ }^{3-6}$ but

From the ${ }^{1}$ Department of Health Behavior and Health Education, University of Michigan School of Public Health, Ann Arbor, Michigan; ${ }^{2}$ Institute for Genome Sciences and Policy, Duke University, Durham, North Carolina; ${ }^{3}$ National Human Genome Center, Howard University, Washington, DC; ${ }^{4}$ Department of Medicine, Howard University, Washington, DC; Departments of ${ }^{5}$ Biostatistics and ${ }^{6}$ Epidemiology, Boston University School of Public Health, Boston, Massachusetts; ${ }^{7}$ Memory and Aging Center, Case Western Reserve University/University Hospitals of Cleveland Memory and Aging, Cleveland, Ohio; ${ }^{8}$ Department of Neurology, Weill Medical College of Cornell University, New York, New York; Departments of ${ }^{9}$ Neurology, ${ }^{10}$ Medicine (Genetics Program), and ${ }^{11}$ Genetics and Genomics, Boston University School of Medicine, Boston, Massachusetts.

Kurt Christensen, MPH, University of Michigan, 300 North Ingalls 5D-04, Ann Arbor, MI 48109-0471.E-mail: kdchrist@umich.edu.

Disclosure: The authors declare no conflict of interest.

Submitted for publication August 17, 2007.

Accepted for publication December 7, 2007.

DOI: 10.1097/GIM.0b013e318164e4cf similar efforts have been made only recently for other diseases. 7,8 One area of recent focus is Alzheimer disease (AD).

$\mathrm{AD}$ is the most common form of dementia among the elderly, affecting an estimated five million individuals in the United States. Well over 10 million Americans are expected to have the condition by 2050 as the population continues to age. ${ }^{9}$ Many risk factors are well-characterized, including age and family history, ${ }^{10-14}$ whereas many others are under investigation, including education level, ${ }^{15,16}$ head trauma, ${ }^{17,18}$ high blood pressure, ${ }^{19}$ caloric intake, and high cholesterol. $.^{20,21} \mathrm{Re}-$ garding genetic factors, rare mutations on genes coding for amyloid precursor protein, presenilin 1, and presenilin 2 have been identified that are deterministic for early-onset AD.22 Apolipoprotein $\mathrm{E}(A P O E)$, in contrast, affects susceptibility to $\mathrm{AD}$ and has three major forms. $A P O E \epsilon 3$, the most common allele, is found in over half the US population. The $\epsilon 4$ allele is associated with increased risk for AD whereas the $\epsilon 2$ allele has a protective effect. ${ }^{23,24}$ The $\epsilon 4$ allele is neither necessary nor sufficient for $\mathrm{AD}$ though, and individuals with the $\epsilon 2$ allele still have risk for $\mathrm{AD}$. APOE variants are also associated with other conditions such as hyperlipoproteinemia and atherosclerosis ${ }^{25}$ and may play a role in the development of macular degeneration. ${ }^{26}$ However, the strong relationship between $A P O E$ and $\mathrm{AD}$ has been repeatedly verified and warrants special attention. ${ }^{27}$ 


\section{Christensen et al.}

The rising prevalence of dementia combined with the relatively high frequency of the APOE $\epsilon 4$ allele, found in about $23 \%$ of the US population, ${ }^{27}$ make AD a useful model for exploring genetic risk communication and assessment for common, complex, adult-onset diseases. The Risk EValuation and Education for Alzheimer Disease (REVEAL) study is a series of clinical trials examining the psychosocial and behavioral impact of providing susceptibility testing with $A P O E$ genotype disclosure to first-degree relatives (FDRs) of people with AD. ${ }^{28}$ Questions considered in the study's first trial included: Who seeks genetic susceptibility testing for $\mathrm{AD}$ and why? What are the psychosocial and behavioral impacts of $A P O E$ genetic susceptibility testing for AD? Although such issues have been explored extensively in cancer genetics and some neurological conditions such as Huntington disease, AD provides a much different context than conditions that develop as a result of dominant or recessive Mendelian genetics. Significant risk for $\mathrm{AD}$ exists even among those without the risk-increasing form of $A P O E$ and researchers have yet to verify methods to delay or prevent the onset of $\mathrm{AD}$. Effective strategies for disclosing an $A P O E$ genotype for $\mathrm{AD}$ risk merit research considering the high prevalence of $\mathrm{AD}$ and the implications of such research on the ever-increasing number of genes being identified as risk factors for other chronic diseases. Results from the REVEAL study to date show that genetic susceptibility testing for $\mathrm{AD}$ is of particular interest to women, college educated persons, and people below the age 60; that $A P O E$ testing can reduce $\mathrm{AD}$ risk perceptions and $\mathrm{AD}$-related anxiety despite presenting identical numerical risk information as family history analysis; and that disclosing increased risk status can motivate long-term care insurance purchasing and behaviors that might reduce $\mathrm{AD}$ risk. ${ }^{28}$ Additional findings are detailed elsewhere. ${ }^{29-35}$

In the first trial of the REVEAL study, nearly $95 \%$ of subjects self-identified as white. ${ }^{28}$ To address this lack of ethnic diversity [Note on terminology: Although the terms "race" and "racial" occasionally appear in this article, this does not mean that the authors subscribe to the view that the human species substructures into biological races. The terms are being used because of their presence in the relevant literature. "Ethnicity" and "ethnic" are our preferred (and dominant) terms, as we believe that they more accurately describe the primary groups on which our study focuses.], a concerted effort was made in the second trial to recruit more minority participants, particularly African Americans. The focus on African Americans was warranted not only by the desire to be more inclusive in our clinical research according to NIH guidelines, but also because this group seems to be at increased risk for AD. ${ }^{13,36}$ Scholars have argued whether and how to include ethnicity as a focus in genetic research. ${ }^{37-42}$ Despite this attention, only a few studies provide data about the challenges and impact of expanding ethnic diversity in research about genetic susceptibility testing. ${ }^{43,44}$

In providing risk assessment to a more diverse study population, we were faced with the dilemma of whether and how to incorporate ethnic group status in risk disclosure procedures. On one hand, many concerns have been raised about linking ethnicity, genetics, and health. Some argue that such work may increase perceptions of genetic inferiority by unintentionally implying that innate differences between racial and ethnic groups are the primary causes of disparities. ${ }^{45}$ Indeed, we are seeing increased attention to what has been called "race-based medicine," a trend that may overemphasize genetic factors and distract attention from social, environmental, and structural contributions to health disparities. ${ }^{46-49}$ On the other hand, the epidemiological data on which risk estimates are typically based suggest significant differences in the lifetime risk of $\mathrm{AD}$ between African Americans and whites, ${ }^{13,17}$ and popular models for genetic cancer risk like the Gail Model incorporate ethnicity into calculations. Some argue that ignoring variations between ethnic groups will not eliminate disparities; and only by focusing attention on these issues will we be able to understand how social, environmental, and behavioral differences interact with biological factors, including genotype. ${ }^{50}$

Advances in genomics may contribute to the reduction of health disparities. ${ }^{51-53}$ If so, we will need to understand better not only the biological impact of specific genotypes and interactions of these genotypes with environment, but also the ways in which different population groups interpret and respond to genetic information. Implicit in this understanding is the need to develop protocols that anticipate and address the social and ethical implications of race and ethnicity in genetic research. ${ }^{54}$ The aim of this article is to describe how researchers in the second REVEAL trial addressed the issue of providing genetic risk assessments for AD to African American participants.

\section{MATERIALS AND METHODS}

The first REVEAL study trial was conducted by a multidisciplinary team of researchers with expertise in neurology, genetics, genetic counseling, psychology, and bioethics. As ethnicity was an important focus of the second trial, the study team expanded its own diversity as an important early step. Researchers focusing on the role of ethnicity in health and genetics research joined the study team, and Howard University, which serves a primarily African American population, became a study site.

REVEAL study researchers considered using many variables in the $\mathrm{AD}$ risk models such as education and history of head injuries. Most variables were ultimately omitted because they were not reliably assessed in the data that served as the foundation for REVEAL study risk models, and the study team concluded that including such variables would unacceptably compromise the models' precision. Self-reported ethnicity was an integral part of the data, though. Therefore, creation of risk models specific to ethnicity warranted further consideration.

The decision to stratify risk estimates by ethnicity in the second REVEAL trial involved three main components: (1) an evaluation of the existing research on African Americans and risk of $\mathrm{AD}$; (2) discussion of the benefits, risks, and limitations of incorporating ethnicity into our calculations of risk estimates; and (3) the feasibility of constructing credible risk curves for African American participants. Once we decided upon the inclusion of African American ethnicity as a variable 
in our risk model, we culled existing data to prepare cumulative risk curves stratified by ethnicity.

\section{Evaluating existing research on African Americans, Alzheimer Disease, and APOE}

Two major issues were addressed at the outset: Are African Americans at increased risk for AD relative to whites? And does APOE genotype have the same impact on AD risk for African Americans as for whites? Data from the Multi-Institutional Research in Alzheimer Genetic Epidemiology (MIRAGE) study and from collaborators were used to answer both questions.

\section{African Americans and Alzheimer disease risk}

Epidemiologic data at the time of protocol development strongly suggested that African Americans are at increased risk for both dementia and AD. ${ }^{55-57}$ Some REVEAL study researchers felt uncomfortable with those assertions, though, considering the small sample sizes of the epidemiological studies that generated such findings. Moreover, the literature was not wholly consistent as one small study in North Carolina found no differences between African Americans and whites. ${ }^{58}$ REVEAL study researchers needed to see more convincing data before they could decide whether to incorporate ethnicity as a factor in $\mathrm{AD}$ risk assessments.

\section{Contribution of APOE genotype to AD risk among African Americans}

Another important point of contention was whether APOE genotype contributes to $\mathrm{AD}$ risk in the same way among African Americans as whites. Some analyses suggested that the contribution of the APOE $\epsilon 4$ allele to Alzheimer risk was weaker for African Americans than for whites. ${ }^{59,60}$ Other studies found interaction effects of $A P O E$ with environment and diet depending on ethnicity or country of origin. ${ }^{36,61-64}$ To further confuse the situation, some of these studies compared US populations with communities in other countries, making findings difficult to generalize to African Americans. They also failed to adjust for the ages of research participants or account for competing risks of death. Moreover, although these studies generally found risk disparities between whites and African Americans, the small numbers of African American participants limited their power to make statistically significant assertions.

\section{The MIRAGE study}

The longitudinal MIRAGE study and collaborative investigators addressed both of the aforementioned epidemiological concerns. The MIRAGE study is the largest genetic epidemiological study of its kind to date, focusing on both African American and white families. ${ }^{13,14,65}$ As a result, it provided a potential basis for clarifying risk profiles for African Americans and risk estimates to FDRs of persons with AD. The study found significantly higher risk for dementia among FDRs of African Americans compared with whites (RR 1.6; 95\% CI 1.4-1.9). The study also found similar effects of APOE genotype on overall $\mathrm{AD}$ risk for African Americans as reported for
Table 1

Relative risk at age 85 (and 95\% CIs) for Alzheimer disease for various APOE genotypes relative to the $\epsilon 3 / \epsilon 3$ genotype ${ }^{a}$

\begin{tabular}{lcc}
\hline & \multicolumn{2}{c}{ Self-identified ethnicity } \\
\cline { 2 - 3 } Genotype & White & African American \\
\hline$\epsilon 3 / \epsilon 3$ & 1.0 & 1.0 \\
$\epsilon 2 / \epsilon 4$ or $\epsilon 3 / \epsilon 4$ & $1.5(1.3-1.8)$ & $1.3(0.9-2.5)$ \\
$\epsilon 4 / \epsilon 4$ & $1.5(1.1-2.0)$ & $1.8(1.1-2.8)$ \\
\hline
\end{tabular}

${ }^{a}$ Data per Green et al. ${ }^{13}$

whites. ${ }^{13} \mathrm{~A}$ comparison of risk through age 85 by self-identified ethnicity and genotype is provided in Table 1.

\section{Weighing reasons for and against risk assessments stratified by ethnicity}

The ethical concerns and social implications of separate risk curves for whites and African Americans, as outlined earlier, still needed to be addressed. The issues that follow were considered by REVEAL study investigators in their decision of whether to incorporate African American ethnicity as a variable in the statistical models used to generate risk estimates in the second trial. Although no specific decision-making framework was formally chosen to guide discussion, ethical principles figured heavily during deliberations. The research team weighed scientific and clinical pros and cons, and also considered perspectives such as duties toward and relationships with research participants. Certainly, the principle of individual beneficence held a key role because we wanted to maximize potential utility of risk information while minimizing potential harms to participants. However, given the legacy of abuse of African Americans in biomedical research, principles of distributive justice (e.g., including African Americans despite imprecise risk estimates) and nonmaleficence (e.g., the danger that African Americans will be stigmatized by such stratification) also figured prominently in the discussions.

\section{Arguments against separate curves}

There is general agreement among genetic researchers that ethnicity, self-defined or otherwise, is a flawed "surrogate for various genetic and nongenetic factors in correlations with health status" 39 and the relationship between African American identity and higher risk of $A D$ is not well explicated. Use of ethnicity in a disease risk model before its role is clearly understood may unwittingly give ethnicity added credence as a biomedical category and a biological cause for disease. ${ }^{38}$ Merely discussing health disparities in the context of genetics may lead to distortions of information and distract attention from inequitable social and environmental factors. ${ }^{66}$ Health disparities are typically the result of many factors, including socioeconomic inequalities, social environment, health care access, health behaviors, and discrimination, ${ }^{67,68}$ and it is likely that at least some of these factors contribute to the disproportionate burden of $\mathrm{AD}$ that African Americans experience. 


\section{Arguments for separate curves}

Although not definitive, the best data available do suggest that African Americans are at higher risk for AD. To ignore ethnicity and related variables in risk estimates could be seen as ignoring important information, resulting in less accurate risk assessments for African Americans. Indeed, researchers have criticized the usefulness of cancer risk assessment models for African Americans that were formulated from data only from whites. ${ }^{69-71}$

Data from a focus group organized at Case Western Reserve University added weight to such concerns. Seven individuals who self-identified as African Americans and had a parent affected by $\mathrm{AD}$ sat down with personnel from the Alzheimer Association and REVEAL study staff to explore whether and how best to disclose AD risk information to African Americans in research focusing on $A P O E$ genotyping for $\mathrm{AD}$ risk. ${ }^{72}$ The seven community participants tended to be female, older (42-73 years old), and well-educated (12-19 years of education). The primary questions of interest are as follows: Should ethnicity be a factor in risk assessment? What are ways of talking about $A P O E, \mathrm{AD}$ risk, and ethnicity? How much detail should the researchers go into about the potential differences in the effect of $A P O E$ on $\mathrm{AD}$ risk for different ethnic groups? And how should we approach the recruitment of African Americans and individuals from other minority groups into REVEAL?

The consensus view of participants was that risk curves based on data from white populations should not preclude the investigators from enrolling African American participants. That feeling was captured well by one participant who asserted, "I would probably feel more comfortable if I had some data that specifically targeted African-Americans, you know? But that wouldn't pull me away from the table. I'm going to be involved at some level because I think it's interesting work and it's important work, so whatever information I can get is valuable." However, African American participants wanted to be informed that initial studies on which risk estimates were based had too few African Americans to generate reliable estimates, and they also wanted to hear that steps were being taken to find other sources of data to make better estimates of specific risks for African Americans. Participants framed these thoughts as a matter of fairness with one saying, "I think you can position yourself as saying we're rectifying a situation."

REVEAL study researchers also considered that many studies suggest differences between racial and ethnic groups in attitudes and beliefs about disease susceptibility and severity. ${ }^{73-75}$ Similar differences in attitudes exist toward genetic testing. ${ }^{76-78}$ Providing stratified risk assessments may better enable us to build on this important literature if the information is deemed by participants to be more appropriate to their communities.

The aforementioned pros and cons were considered in detail by REVEAL study investigators in a series of conference calls and at a 2-day investigator retreat at the project's home site in Boston. At this meeting, investigators from the four participating universities-Boston University, Case Western Reserve
University, Cornell University, and Howard University-convened to discuss study goals and challenges. Given the study's focus on the psychosocial and behavioral impact of genetic testing rather than the etiology of $\mathrm{AD}, \mathrm{REVEAL}$ study researchers weighed focus group data on African American participants' preferences more heavily than the hypothetical concerns of academic researchers about the utilization of race and ethnicity in disease risk models. The research team considered the risk differences between African Americans and whites to be meaningfully higher, and argued that providing risk assessments that ignored ethnicity would be a disservice to study participants. In addition, study team members who participated in the first trial struggled with their own concerns about giving minority participants risk estimates based on models that excluded their ethnic identification. Investigators concluded that potential study harms could be minimized through vigilant monitoring of participant responses and that stratifying risk curves by ethnicity would provide empirical data that would inform the ethical debate on future studies in $\mathrm{AD}$ and other common, complex diseases.

\section{Feasibility and creation of customized risk curves}

The evidence presented above was believed to favor establishing customized risk assessments for African Americans. Our focus then turned to the best way to establish cumulative risk curves that might help participants understand their agespecific risk and potentially reduce anxiety about developing AD. Models for AD risk that incorporated APOE genotype did not exist for African Americans, but the study team concluded that risk estimates for FDRs of patients with AD could be created using data from the aforementioned MIRAGE study. The MIRAGE study recruited patients with AD from 17 specialty clinics between May 1991 and March 2001, using methods published elsewhere. ${ }^{14,65,79}$ The dementia risk models stratified by ethnicity as presented by Green et al. ${ }^{13}$ provided a basis for creating $\mathrm{AD}$ models for the REVEAL study.

Maximum likelihood procedures akin to a standard KaplanMeier survival analysis but incorporating missing age information were used to construct risk curves. First, gender-specific risk curves for FDRs of white patients with AD were created from epidemiological data on 14,907 FDRs of white patients with $\mathrm{AD}$. In the same manner, data from 3,007 African American FDRs were used to generate gender-specific risk profiles for African American FDRs. Comparison curves for general population risk were also created for each population group per the same methodology using data from 2,157 white and 368 African American spouses of patients with $\mathrm{AD}$ as the source.

The next step was to modify those curves to incorporate APOE genotype. The curves for FDRs of patients with $\mathrm{AD}$ as described above were assumed to be equivalent to the risk curves for FDR subjects with $\epsilon 3 / \epsilon 3$ genotype. We then used data from a meta-analysis of nearly 50 studies worldwide that examined the odds of developing $\mathrm{AD}$ for specific gender, age, and $A P O E$ combinations ${ }^{80}$ relative to the $\epsilon 3 / \epsilon 3$ genotype to transform our FDR curves into gender and age-dependent AD 


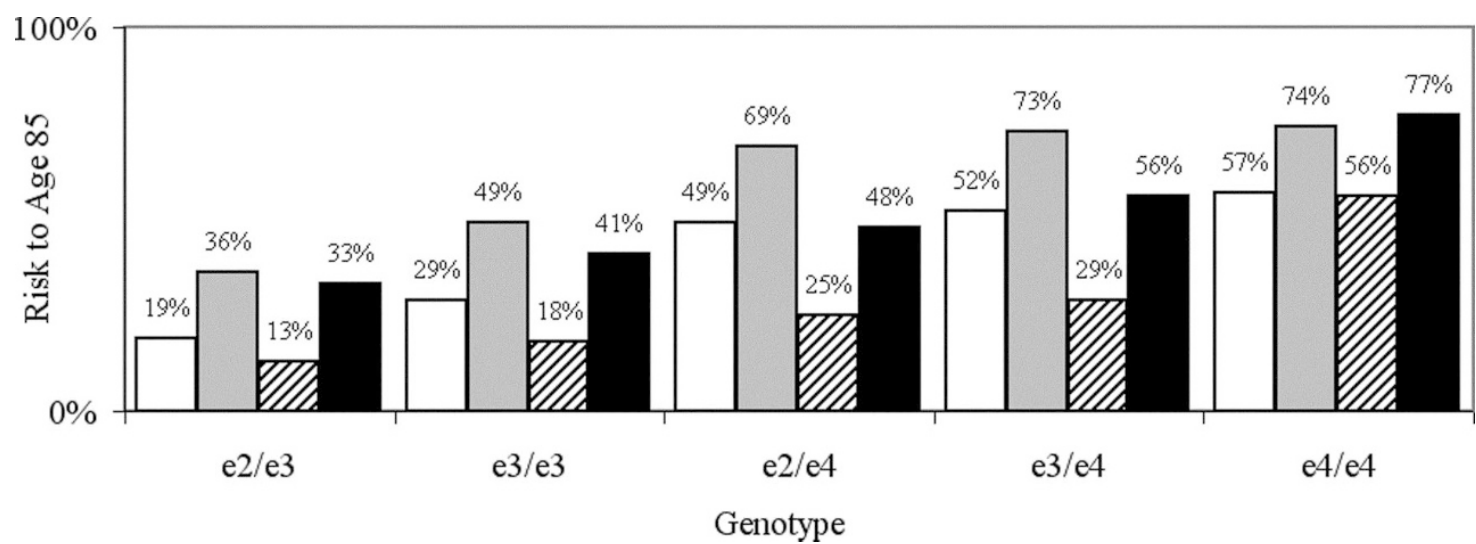

Fig. 1. Cumulative risk estimates to age 85 for Alzheimer disease (AD) for first-degree relatives of AD patients based on APOE genotype, gender, and ethnicity. $\square$ White females; $\square$ African American females; 四 white males; and African American males.

risk information for specific $A P O E$ genotypes. Based on the evidence that the effect of $A P O E$ genotype is similar in whites and African Americans as presented earlier, we used the same odds ratio data on both the white and African American curves to derive our final ethnicity-specific risk curves. A more thorough explanation of how the risk curves were constructed is provided by Cupples et al. ${ }^{33}$

\section{RESULTS}

The processes detailed above were taken into consideration to create a study protocol where African American and white study participants received $\mathrm{AD}$ risk estimates specific to their ethnicities.

\section{Cumulative risk curves}

A key outcome of our efforts was construction of cumulative risk curves stratified by ethnicity. These risk curves for FDRs of patients with $\mathrm{AD}$ were created to incorporate age, gender, selfidentified ethnicity, and $A P O E$ genotype. Risk estimates through age 85 ranged from 19 to $57 \%$ for white females, 36 to $74 \%$ for African American females, 13 to $56 \%$ for white males, and 33 to 77\% for African American males. The lower-end estimates correspond to an $\epsilon 2 / \epsilon 3$ genotype whereas the higher-end estimates correspond to an $\epsilon 4 / \epsilon 4$ genotype. As reflected in Figure 1, African Americans were given markedly higher risk estimates than whites, in accordance with the higher risk estimates found for these groups in the MIRAGE study. Females were found to be at modestly higher risk compared with males for all genotypes aside from $\epsilon 4 / \epsilon 4$. Also as seen in Figure 1, the $\epsilon 2$ allele confers a protective effect, whereas the $\epsilon 4$ allele elevates risk and the $\epsilon 3$ allele represents intermediate risk. Data in Figure 1 match well with data provided in other studies. ${ }^{81}$ Examples of the cumulative risk curves stratified by ethnicity and genotype are shown in Figure 2, with risk being $<10 \%$ until age 60 . At that point, the risk increases for all ethnic groups and genotypes, but particularly so for African Americans. Examination of the curves shows that $A P O E$ genotype has stronger effects at younger ages. After age 65, the impact of APOE ge- notype on $\mathrm{AD}$ risk lessens. Confidence intervals were not included on the risk curves to make the information easier to understand for a study participant but disclosure procedures include verbal statements that an individual's risk for $\mathrm{AD}$ is "influenced by other factors that are not taken into account in this curve" and the risk we convey to each participant is merely "an estimate based on our current knowledge." These statements were reinforced in written materials provided to the study participants. These curves were ultimately used in the second REVEAL trial that disclosed $\mathrm{AD}$ risk to 276 study participants, 53 (19\%) of whom self-identified as African American.

\section{DISCUSSION}

The REVEAL study is among the first to incorporate ethnicity into a multivariable genetic risk assessment for a common, complex disease such as AD. An analysis of the psychosocial and behavioral impact of risk information in this study will be the focus of future articles, but there is reason to believe that African Americans will respond well to risk disclosure based on genetic information that takes ethnicity into account. In a national telephone survey that included 375 African Americans and 960 whites, African Americans were more likely than whites to indicate that they would want genetic testing for both "untreatable diseases" in general and Huntington disease specifically. ${ }^{82}$ Similarly, a survey of 174 African Americans and 278 whites specifically focusing on attitudes toward predictive testing for $\mathrm{AD}$ found that African Americans expected fewer negative consequences from a positive genetic test result for $\mathrm{AD}$ than whites. ${ }^{78}$ The REVEAL study will add to this literature with respect to predictive genetic testing for common, complex conditions.

We believe that our work offers an instructive example of protocol development that begins to address concerns about incorporating ethnicity into genetic risk assessment and communication. The most important step is recognizing that developing research protocols to be appropriate for minority communities requires more than recruiting study participants from communities of color, and expanding our research team 
Risk of AD by APOE in African American Men

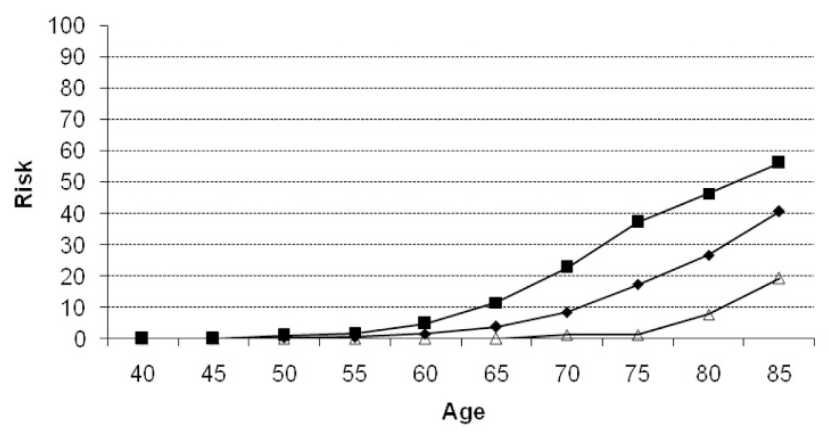

$\rightarrow$-APOE $34 \longrightarrow$ General Population $\multimap$ First Degree

Risk of AD by APOE in African American Women

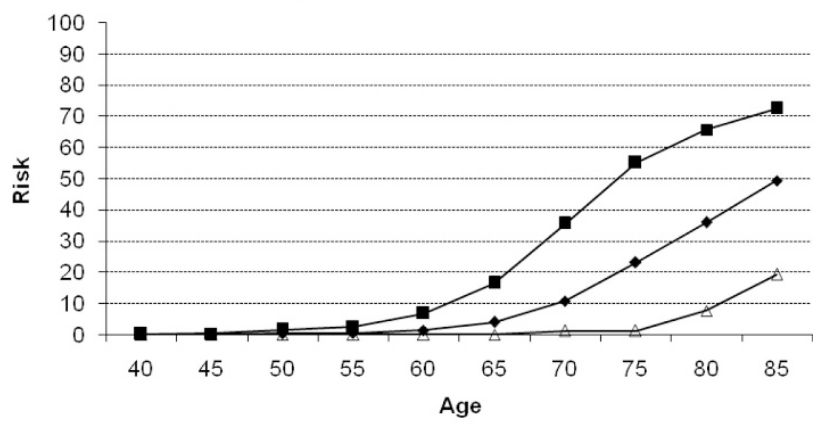

-APOE $34 \triangle$ General Population $\rightarrow$ First Degree
Risk of AD by APOE in White Men

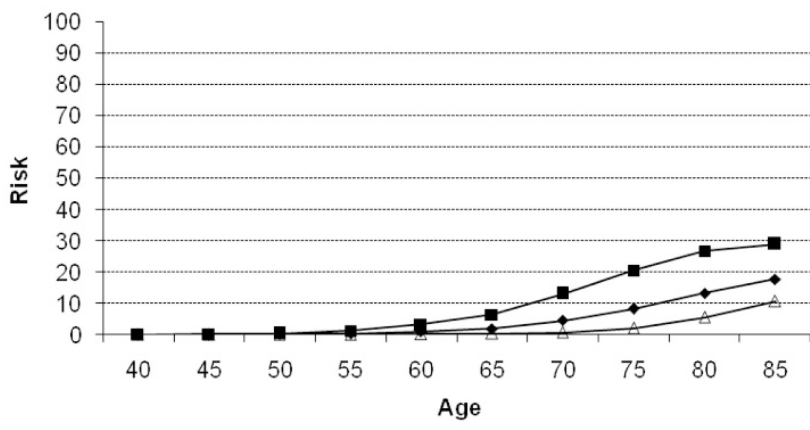

-APOE $34 \rightarrow$ General Population $\rightarrow$ First Degree

Risk of AD by APOE in White Women

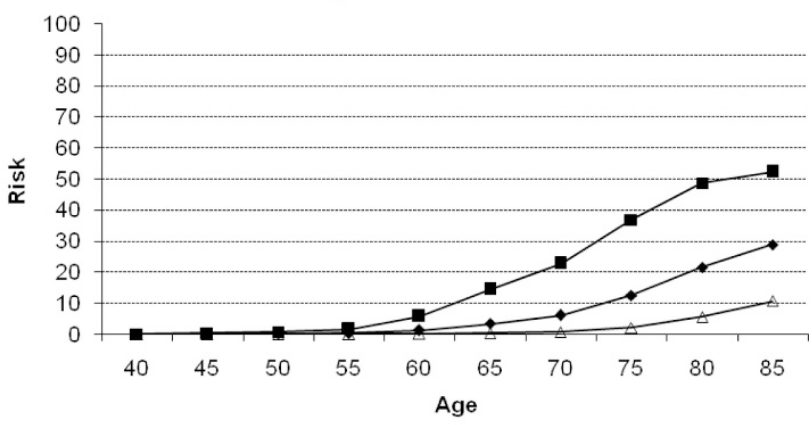

-APOE $34 \multimap$ General Population $\rightarrow$ First Degree

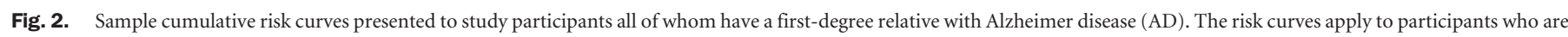

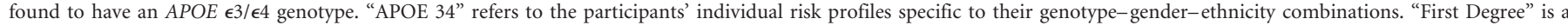

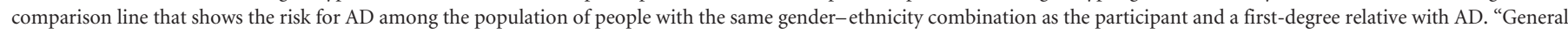

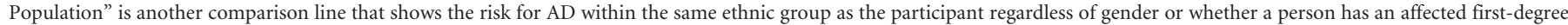
relative. Explanations of each line are provided verbally to study participants.

to include more investigators with expertise in the ways health and genetics research intersect with ethnic identity helped us think through the implications of our proposals. It took great time and effort to perform a thorough epidemiological review, to deliberate these issues regularly not only within the research team, but also with community members via a focus group, and to find and manipulate a database with sufficient diversity to create the appropriate risk models. Our study shows, though, that such steps can be successfully implemented into genetics research when issues of ethnicity are given due emphasis.

Admittedly, more could be done within the REVEAL study and research on genetic susceptibility testing in general. Many scholars argue for engagement approaches where community members are involved as early as the planning stages of research to ensure that it is responsive to the concerns of marginalized populations. ${ }^{51,83,84}$ Other approaches could simply involve engaging the public through more frequent community forums. Focus group input played an important role in influencing decisions on our study, but a single group does not represent a community as a whole, as echoed by a separate informal focus group convened by our study group to discuss African American participation in AD research. ${ }^{72}$ Still, the strategy used to develop the REVEAL protocol does provide an example of a successful study of genetic susceptibility testing that takes into consideration the significant ethical, legal, and social implications of such research.

The REVEAL study also demonstrates how a lack of epidemiological data can create problems for researchers and research participants alike. Access to the raw data from the MIRAGE study played a critical role in our decision to stratify risk assessments according to self-identified ethnicity. Still, MIRAGE data were only used to create the risk curves for the $\epsilon 3 / \epsilon 3$ genotype and curves that ignored genotype, and data from additional sources were used to transform the $\epsilon 3 / \epsilon 3$ curves into the other genotype-specific curves. Such manipulations reduce the precision of risk estimates and introduce unknown biases. What's more, the appropriateness of our risk models for populations other than whites and African Americans is questionable. Myriad reasons exist for this lack of good $\mathrm{AD}$ data on minority communities. A few major themes include attitudes toward research objectives, ${ }^{85}$ barriers to participation such as distance and finances, ${ }^{86}$ and attitudes toward $\mathrm{AD}$ in general. ${ }^{34}$ Strategies such as improving community awareness about $\mathrm{AD}$, addressing practical considerations such as accessibility of the research setting, and involving community leaders in planning and execution of research can help to boost minority participation in dementia studies. ${ }^{87}$ Such strategies need to be implemented more frequently if research in- 
stitutions hope to develop the kind of long-term partnerships that can be of greatest benefit to communities of color.

We recognize that we are only in the beginning stages of developing risk models for $\mathrm{AD}$ that might be used to disclose personalized risk information. The data used to establish our genotype-specific and comparison risk curves, for example, do not account for variables such as shared lifestyle or education (see Green et al. ${ }^{13}$ for a more thorough discussion of the limitations of our curves). We hope that over time, research will tease apart the causes of risk differences and causes of outcome disparities (whether biological, behavioral, social, and economic, or other). We also hope to better understand how different groups with different cultures respond to risk information, and how best to communicate risk to different groups. This will require the utilization of more comprehensive research designs that account for the complex interactions among genes, culture, access to care, caregiving patterns of those with or at risk of $\mathrm{AD}$, and a host of other biological and nonbiological factors. As we learn more about the roles of these variables in the etiology of $\mathrm{AD}$, we should not only be better able to develop more refined models, but also perhaps (and more importantly) to prevent or at least delay the disease.

In the meantime, it is important that we carefully confront the issue of ethnicity in genetic risk assessments rather than shy away from it. Family history is among the strongest risk factors for most diseases, and susceptibility genes are rapidly being identified for common conditions such as diabetes, arthritis, and heart disease. ${ }^{88}$ Many of these conditions demonstrate disparities in morbidity and mortality according to ethnicity similar to those seen in $\mathrm{AD}$. APOE genotyping in the context of $\mathrm{AD}$ therefore serves as a useful paradigm to explore the important issue of ethnicity in the context of a genetic risk assessment. Developing culturally appropriate risk communication strategies will be critical to ensure that the benefits of technological advances are fairly distributed. This goal merits particular attention considering the expanding diversity of our nation.

\section{ACKNOWLEDGMENTS}

This study was funded by the National Institutes of Health (R01 AG02213-The REVEAL Study and R01 AG09029 - the MIRAGE Study). Support for recruitment and clinical research services was also provided by the Boston University Alzheimer's Disease Center (P30 AG13846), Boston University General Clinical Research Center (GCRC) (M01 RR00533), and Howard University GCRC (M01 RR10284). R.C.D. is supported by the Center for Public Genomics at Duke University (P50 HG003391).

The authors appreciate the assistance of Winston Chung and Clara Chen at the Boston University Alzheimer's Disease Research and Clinical Program for their assistance with manuscript preparation.

\section{References}

1. Fischhoff B. Why (cancer) risk communication can be hard. J Natl Cancer Inst Monographs 1999;25:7-13.
2. Gigerenzer G, Edwards A. Simple tools for understanding risks: from innumeracy to insight. Br Med J 2003;327:741-744.

3. Geller G, Botkin JR, Green MJ, Press N, et al. Genetic testing for susceptibility to adultonset cancer. The process and content of informed consent. JAMA 1997;277:1467-1474.

4. Aktan-Collan K, Mecklin JP, de la Chapelle A, Peltomaki P, et al. Evaluation of a counselling protocol for predictive genetic testing for hereditary non-polyposis colorectal cancer. J Med Genet 2000;37:108-113.

5. Burke W, Petersen G, Lynch P, Botkin J, et al. Recommendations for follow-up care of individuals with an inherited predisposition to cancer. I. Hereditary nonpolyposis colon cancer. Cancer Genetics Studies Consortium. JAMA 1997;277:915-919.

6. Burke W, Daly M, Garber J, Botkin J, et al. Recommendations for follow-up care of individuals with an inherited predisposition to cancer. II. BRCA1 and BRCA2. Cancer Genetics Studies Consortium. JAMA 1997;277:997-1003.

7. Anonymous. International Huntington Association and the World Federation of Neurology Research Group on Huntington Chorea. Guidelines for the molecular genetics predictive test in Huntington disease. J Med Genet 1994;31:555-559.

8. Simonoff E. Genetic counseling in autism and pervasive developmental disorders. J Autism Dev Disord 1998;28:447-456.

9. Hebert LE, Scherr PA, Bienias JL, Bennett DA, et al. Alzheimer disease in the US population: prevalence estimates using the 2000 census. Arch Neurol 2003;60:1119-1122.

10. Pedersen NL, Gatz M, Berg S, Johansson B. How heritable is Alzheimer's disease late in life? Findings from Swedish twins. Ann Neurol 2004;55:180-185.

11. Brickell KL, Steinbart EJ, Rumbaugh M, Payami H, et al. Early-onset Alzheimer disease in families with late-onset Alzheimer disease: a potential important subtype of familial Alzheimer disease. Arch Neurol 2006;63:1307-1311.

12. Rocca WA, Amaducci LA, Schoenberg BS. Epidemiology of clinically diagnosed Alzheimer's disease. Ann Neurol 1986;19:415-424.

13. Green RC, Cupples LA, Go R, Benke KS, et al. Risk of dementia among white and African American relatives of patients with Alzheimer disease. JAMA 2002;287:329-336.

14. Lautenschlager NT, Cupples LA, Rao VS, Auerbach SA, et al. Risk of dementia among relatives of Alzheimer's disease patients in the MIRAGE study: what is in store for the oldest old? Neurology 1996;46:641-650.

15. Manly JJ, Byrd DA, Touradji P, Stern Y. Acculturation, reading level, and neuropsychological test performance among African American elders. Appl Neuropsychol 2004; 11:37-46.

16. Manly JJ, Schupf N, Tang MX, Stern Y. Cognitive decline and literacy among ethnically diverse elders. J Geriatr Psychiatry Neurol 2005;18:213-217.

17. Bachman DL, Green RC, Benke KS, Cupples LA, et al. Comparison of Alzheimer's disease risk factors in white and African American families. Neurology 2003;60:1372-1374.

18. Guo Z, Cupples LA, Kurz A, Auerbach SH, et al. Head injury and the risk of AD in the MIRAGE study. Neurology 2000;54:1316-1323.

19. Skoog I, Gustafson D. Update on hypertension and Alzheimer's disease. Neurol Res 2006;28:605-611.

20. Evans RM, Emsley CL, Gao S, Sahota A, et al. Serum cholesterol, APOE genotype, and the risk of Alzheimer's disease: a population-based study of African Americans. Neurology 2000;54:240-242.

21. Luchsinger JA, Tang MX, Shea S, Mayeux R. Caloric intake and the risk of Alzheimer disease. Arch Neurol 2002;59:1258-1263.

22. Morris JC. Dementia Update 2005. Alzheimer Dis Assoc Disord 2005;19:100-117.

23. Kukull WA, Higdon R, Bowen JD, McCormick WC, et al. Dementia and Alzheimer disease incidence; a prospective cohort study. Arch Neurol 2002;59:1737-1746.

24. Graff-Radford NR, Green RC, Go RCP, Hutton ML, et al. Association between apolipoprotein E genotype and Alzheimer disease in African American subjects. Arch Neurol 2002;59:594-600.

25. Mahley RW, Rall SC Jr. Apolipoprotein E. Far more than a lipid transport protein. Annu Rev Genomics Hum Genet 2000;1:507-537.

26. Thakkinstian A, Bowe S, McEvoy M, Smith W, et al. Association between apolipoprotein E polymorphisms and age-related macular degeneration: a HuGE review and meta-analysis. Am J Epidemiol 2006;164:813-822.

27. Raber J, Huang Y, Ashford JW. ApoE genotype accounts for the vast majority of AD risk and AD pathology. Neurobiol Aging 2004;25:641-650.

28. Roberts JS, Cupples LA, Relkin NR, Whitehouse PJ, et al. Genetic risk assessment for adult children of people with Alzheimer's disease: the Risk Evaluation and Education for Alzheimer's Disease (REVEAL) study. J Geriatr Psychiatry Neurol 2005;18:250-255.

29. Gooding HC, Linnenbringer EL, Burack J, Roberts JS, et al. Genetic susceptibility testing for Alzheimer disease: motivation to obtain information and control as precursors to coping with increased risk. Patient Educ Couns 2006;64:259-267.

30. Lock M, Freeman J, Sharples R, Lloyd S. When it runs in the family: putting susceptibility genes in perspective. Public Underst Sci 2006;15:277-300.

31. Hurley AC, Harvey FR, Roberts JS, Wilson-Chase C, et al. Genetic susceptibility for Alzheimer's disease: why did adult offspring seek testing? Am J Alzheimers Dis Other Demen 2005;20:374-381.

32. Marteau TM, Roberts S, LaRusse S, Green RC. Predictive genetic testing for Alzheimer's disease: impact upon risk perception. Risk Anal 2005;25:397-404. 


\section{Christensen et al.}

33. Cupples LA, Farrer LA, Sadovnick AD, Relkin N, et al. Estimating risk curves for first-degree relatives of patients with Alzheimer's disease: the REVEAL study. Genet Med 2004;6:192-196.

34. Roberts JS, LaRusse SA, Katzen H, Whitehouse PJ, et al. Reasons for seeking genetic susceptibility testing among first-degree relatives of people with Alzheimer disease. Alzheimer Dis Assoc Disord 2003;17:86-93.

35. Roberts JS, Barber M, Brown TM, Cupples LA, et al. Who seeks genetic susceptibility testing for Alzheimer's disease? Findings from a multisite, randomized clinical trial. Genet Med 2004;6:197-203.

36. Tang MX, Stern Y, Marder K, Bell K, et al. The APOE-epsilon4 allele and the risk of Alzheimer disease among African Americans, whites, and Hispanics. JAMA 1998;279: 751-755.

37. Reardon J. Race to the finish: identity and governance in an age of genomics. Princeton, NJ: Princeton University Press, 2005.

38. Duster T. Medicine. Race and reification in science. Science 2005;307:1050-1051.

39. Royal CD, Dunston GM. Changing the paradigm from "race" to human genome variation. Nat genet 2004;36:S5.

40. Kittles RA, Weiss KM. Race, ancestry, and genes: implications for defining disease risk. Annu Rev Genomics Hum Genet 2003;4:33-67.

41. Cyrus-David MS. The future of women of minority race/ethnicity in breast cancer chemoprevention therapy. Ethn Dis 2006;16:216-222.

42. Shields AE, Fortun M, Hammonds EM, King PA, et al. The use of race variables in genetic studies of complex traits and the goal of reducing health disparities: a transdisciplinary perspective. Am Psychol 2005;60:77-103.

43. Halbert CH, Brewster K, Collier A, Smith C, et al. Recruiting African American women to participate in hereditary breast cancer research. J Clin Oncol 2005;23:7967-7973.

44. Halbert CH, Gandy OH Jr, Collier A, Shaker L. Intentions to participate in genetics research among African American smokers. Cancer Epidemiol Biomarkers Prev 2006; 15:150-153.

45. Condit C, Bates B. How lay people respond to messages about genetics, health, and race. Clin Genet 2005;68:97-105.

46. Lee SS. Racializing drug design: implications of pharmacogenomics for health disparities. Am J Public Health 2005;95:2133-2138.

47. Sankar P, Cho MK, Condit CM, Hunt LM, et al. Genetic research and health disparities. JAMA 2004;291:2985-2989.

48. Krieger N. Stormy weather: race, gene expression, and the science of health disparities. Am J Public Health 2005;95:2155-2160.

49. Muntaner C, Nieto FJ, O'Campo P. The bell curve: on race, social class, and epidemiologic research. Am J Epidemiol 1996;144:531-536.

50. Bonham VL, Warshauer-Baker E, Collins FS. Race and ethnicity in the genome era: the complexity of the constructs. Am Psychol 2005;60:9-15.

51. Citrin T, Modell S, Gwinn MD, Bedrosian S, et al. Genomics and public health: ethical, legal, and social issues. Genomics and population health: United States 2003. Chapter 8. Atlanta, GA: The Office of Genomics and Disease Prevention, Centers for Disease Control and Prevention (CDC), 2004:51-59.

52. Fine MJ, Ibrahim SA, Thomas SB. Race and genetics in health disparities research. Am J Public Health 2005;95:2125-2128.

53. Qureshi N, Kai J. Genomic medicine for underserved minority populations in family medicine. Am Fam Physician 2005;72:386-387.

54. Ossorio P, Duster T. Race and genetics: controversies in biomedical, behavioral, and forensic sciences. Am Psychol 2005;60:115-128.

55. Folstein MF, Bassett SS, Anthony JC, Romanoski AJ, et al. Dementia: case ascertainment in a community survey. J Gerontol 1991;46:M132-M138.

56. Schoenberg BS, Anderson DW, Haerer AF. Severe dementia. Prevalence and clinical features in a biracial US population. Arch Neurol 1985;42:740-743.

57. Heyman A, Fillenbaum G, Prosnitz B, Raiford K, et al. Estimated prevalence of dementia among elderly black and white community residents. Arch Neurol 1991;48:594-598.

58. Fillenbaum GG, Heyman A, Huber MS, Woodbury MA, et al. The prevalence and 3 -year incidence of dementia in older black and white community residents. J Clin Epidemiol 1998;51:587-595.

59. Hendrie HC, Hall KS, Ogunniyi A, Gao S. Alzheimer's disease, genes, and environment: the value of international studies. Can J Psychiatry 2004;49:92-98.

60. Morgan OS, Eldemire DA, Thesiger CH, Luseko J, et al. APOE allele frequencies in demented and nondemented elderly Jamaicans. Ann Neurol 1998;43:545.
61. Maestre G, Ottman R, Stern Y, Gurland B, et al. Apolipoprotein E and Alzheimer's disease: ethnic variation in genotypic risks. Ann Neurol 1995;37:254-259.

62. Sahota A, Yang M, Gao S, Hui SL, et al. Apolipoprotein E-associated risk for Alzheimer's disease in the African-American population is genotype dependent. Ann Neurol 1997;42:659-661.

63. Gureje O, Ogunniyi A, Baiyewu O, Price B, et al. APOE epsilon4 is not associated with Alzheimer's disease in elderly Nigerians. Ann Neurol 2006;59:182-185.

64. Evans DA, Bennett DA, Wilson RS, Bienias JL, et al. Incidence of Alzheimer disease in a biracial urban community: relation to apolipoprotein E allele status. Arch Neurol 2003;60:185-189.

65. Farrer LA, Cupples LA, Blackburn S, Kiely DK, et al. Interrater agreement for diagnosis of Alzheimer's disease: the MIRAGE study. Neurology 1994;44:652-656.

66. Kahn J. Misreading race and genomics after BiDil. Nat Genet 2005;37:655-656.

67. CDC. Health Disparities Experienced by Black or African Americans-United States MMWR Morb Mortal Wkly Rep 2005;54:1-3.

68. Williams DR, Neighbors HW, Jackson JS. Racial/ethnic discrimination and health: findings from community studies. Am J Public Health 2003;93:200-208.

69. Bondy ML, Newman LA. Breast cancer risk assessment models: applicability to African-American women. Cancer 2003;97:230-235.

70. Simon MS, Korczak JF, Yee CL, Malone KE, et al. Breast cancer risk estimates for relatives of white and African American women with breast cancer in the Women's Contraceptive and Reproductive Experiences Study. J Clin Oncol 2006;24:2498-2504.

71. Grann VR, Jacobson JS, Troxel AB, Hershman D, et al. Barriers to minority participation in breast carcinoma prevention trials. Cancer 2005;104:374-379.

72. Barber M, Whitehouse PJ. Susceptibility testing for Alzheimer's disease: race for the future. Lancet Neurol 2002;1:10.

73. Roberts JS, Connell CM, Cisewski D, Hipps YG, et al. Differences between African Americans and whites in their perceptions of Alzheimer disease. Alzheimer Dis Assoc Disord 2003;17:19-26.

74. Wilson RP, Freeman A, Kazda MJ, Andrews TC, et al. Lay beliefs about high blood pressure in a low- to middle-income urban African-American community: an opportunity for improving hypertension control. Am J Med 2002;112:26-30.

75. Kumanyika S, Savage DD, Ramirez AG, Hutchinson J, et al. Beliefs about high blood pressure prevention in a survey of blacks and Hispanics. Am J Prev Med 1989;5:21-26.

76. Donovan KA, Tucker DC. Knowledge about genetic risk for breast cancer and perceptions of genetic testing in a sociodemographically diverse sample. J Behav Med 2000;23:15-36.

77. Hughes C, Gomez-Caminero A, Benkendorf J, Kerner J, et al. Ethnic differences in knowledge and attitudes about BRCA1 testing in women at increased risk. Patient Educ Couns 1997;32:51-62.

78. Hipps YG, Roberts JS, Farrer LA, Green RC. Differences between African Americans and whites in their attitudes toward genetic testing for Alzheimer's disease. Genet Test 2003;7:39-44.

79. Demissie S, Green RC, Mucci L, Tziavas S, et al. Reliability of information collected by proxy in family studies of Alzheimer's disease. Neuroepidemiol 2001;20:105-111.

80. Farrer LA, Cupples LA, Haines JL, Hyman B, et al. Effects of age, sex and ethnicity on the association between apolipoprotein E genotype and Alzheimer disease: a metaanalysis. JAMA 1997;278:1349-1356.

81. Murrell JR, Price B, Lane KA, Baiyewu O, et al. Association of apolipoprotein E genotype and Alzheimer disease in African Americans. Arch Neurol 2006;63:431-434.

82. Singer E, Antonucci T, van Hoewyk J. Racial and ethnic variations in knowledge and attitudes about genetic testing. Genet Test 2004;8:31-43.

83. Cunningham-Burley S. Public knowledge and public trust. Community Genet 2006; 9:204-210.

84. Smith BH, Watt GC, Campbell H, Sheikh A. Genetic epidemiology and primary care. Br J Gen Pract 2006;56:214-221.

85. Holston EC. Stigmatization in Alzheimer's disease research on African American elders. Issues Ment Health Nurs 2005;26:1103-1127.

86. Harrell LE, Callaway R, Powers R. Autopsy in dementing illness: who participates? Alzheimer Dis Assoc Disord 1993;7:80-87.

87. Welsh KA, Ballard E, Nash F, Raiford K, et al. Issues affecting minority participation in research studies of Alzheimer disease. Alzheimer Dis Assoc Disord 1994;8(suppl 4):38-48.

88. Altshuler D, Brooks LD, Chakravarti A, Collins FS, et al. A haplotype map of the human genome. Nature 2005;437:1299-1320. 